\title{
Water management practices can affect salinity in rice fields
}

\author{
Steven C. Scardaci \\ Michael C. Shannon \\ Stephen R. Grattan \\ Austine U. Eke \\ Stacey R. Roberts \\ S. Goldman-Smith \\ James E. Hill
}

\section{Water management practices in} California rice production can affect salinity in the field. This is particularly important because rice is one of the most sensitive crops to salinity. We extensively monitored salinity patterns in dozens of rice fields in Colusa and Glenn counties, in order to determine how salinity varies from basin to basin and to compare salinity patterns under different irrigation systems. We found that the fields most vulnerable to salinity damage were those with higher soil salinity and using irrigation water sources initially high in salinity, particularly nondistrict sources that are combinations of well and drain water. Long water holding periods, while effective in reducing pesticide concentrations in rice fields, can contribute to salinity increases in bottom basins. Salinity can increase with either conventional or static irrigation management systems, but the salinity pattern in the field will be different.

\footnotetext{
N ore than 470,000 acres of rice were planted in California in 2001, with a production value of $\$ 138$ million (according to the California Agricultural Statistics Service). Rice is different from the state's other important field crops in that it is grown in basins under continuously flooded conditions. Rice has a unique anatomical
}
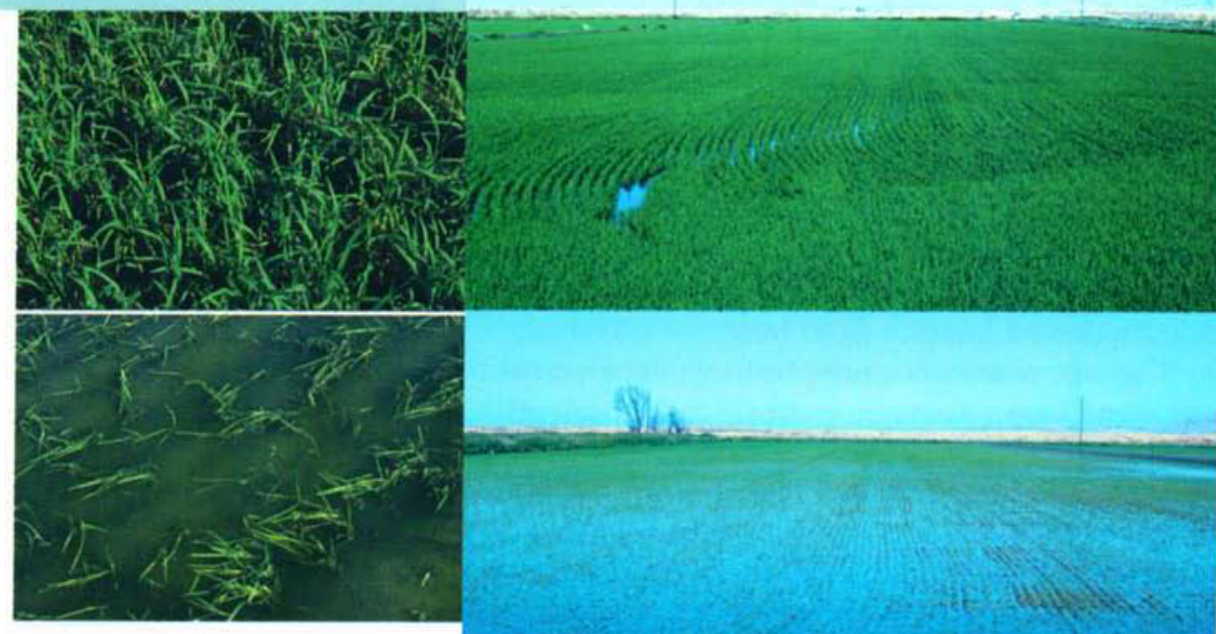

Grown in flooded conditions, rice is one of the most sensitive crops to salinity. In California, rice is generally grown in a series of basins, with water running from upper to lower basins before draining out. The authors found that salinity stress and yield reductions tend to increase from upper basins, above, to bottom basins, below.

feature called aerenchyma (large internal air spaces), which provide oxygen to roots, allowing the plant to thrive under flooded conditions. Most weed species cannot survive in this environment.

Unlike other crops, rice is seeded directly into saturated fields by aircraft, providing a uniform stand. Historically, most rice has been grown using a conventional "flow-through" system where irrigation water flows sequentially through a series of basins starting at the top and ending at the bottom. Weirs between basins control water depth and flow, and excess water in the bottom basin spills into a drainage ditch.

Water management practices in California rice production have changed substantially since the 1970 s and early 1980 s, when water was held in the field for short periods of several days. In the early 1970s, water quality studies in California indicated that the salinity of rice-field outflows averaged about $30 \%$ higher than inflow water in 14 fields (Henderson et al. 1974). In five fields from Colusa and Glenn counties, the salinity of outflow water averaged about $60 \%$ more than inflow water. By the early 1990s, rice growers were holding water in basins for up to 30 days (May to early June) after a pesticide application (Lee et al. 1993). These holding periods were the primary means of reducing pesticide residues and were required by the state Department of Pesticide Regulation to fulfill the Central Valley Regional Water Quality Control Plan. Rice growers adopted closed systems, which recirculate water within basins, or constructed static water basins, in which water flows into a single basin without an outflow. They also developed gravity systems, in which drainage water from the bottom basin bypasses the drain by redirecting it to the top basin of another series of lower-elevation basins.

During the late 1980s and early 1990s California experienced a longterm drought, resulting in further tailwater outflow restrictions and a no-spill policy, which prohibited the discharge of field water from bottom basins into waterways after June 30 or July 15 (1992 to 1994) in some rice- 
growing areas. In the early 1990s some rice growers noticed problems with stand establishment in parts of their fields. They suggested that salinity problems might develop with the longer water holding periods and/or in closed irrigation systems. The lateseason no-spill policy was discontinued in 1995, and other less restrictive modifications have been made since.

Rice is sensitive to salinity, particularly during the early seedling (Maas 1990) and pollination stages (Khatun and Flowers 1995). Salinity stress during these periods may reduce rice growth and/or yield. In rice, salinity during the seedling stage causes a reduction in stand density and seedling biomass (Shannon et al. 1998). During pollination salinity may cause panicle blanking (sterile florets) or sterility, leading to a reduction in grain yield. Rice is more tolerant of salinity at other growth stages, and salinity stress during these periods has less impact on yield (see Grattan et al, p. 189).

We initiated salinity investigations in the early 1990s to determine if salinity was adversely affecting rice production in California and to determine impacts on yield. Different irrigation systems that limit the discharge of field water into waterways were monitored to evaluate the distribution of salinity within particular fields.

\section{Irrigation water salinity}

Thirteen irrigation district and nondistrict water sources in Colusa and Glenn counties were monitored for salinity in June, July and August from 1993 through 1995. District water comes directly from an irrigation agency such as the Glenn-Colusa Irrigation District, while nondistrict water provides a mix of river water, well water and/or recaptured drain water. Data indicated that most irrigation waters had low mean summertime salinity levels. For example, the electrical conductivity of the inflow water $\left(\mathrm{EC}_{\mathrm{w}}\right)$ - which goes up as water salinity increases - was less than 0.7 deciSiemens/meter ( $\mathrm{dS} / \mathrm{m}$ ), but some sources had moderate levels of 0.7 to $1.47 \mathrm{dS} / \mathrm{m}$ (fig. 1). (DeciSiemens per meter is a measure of the electrical

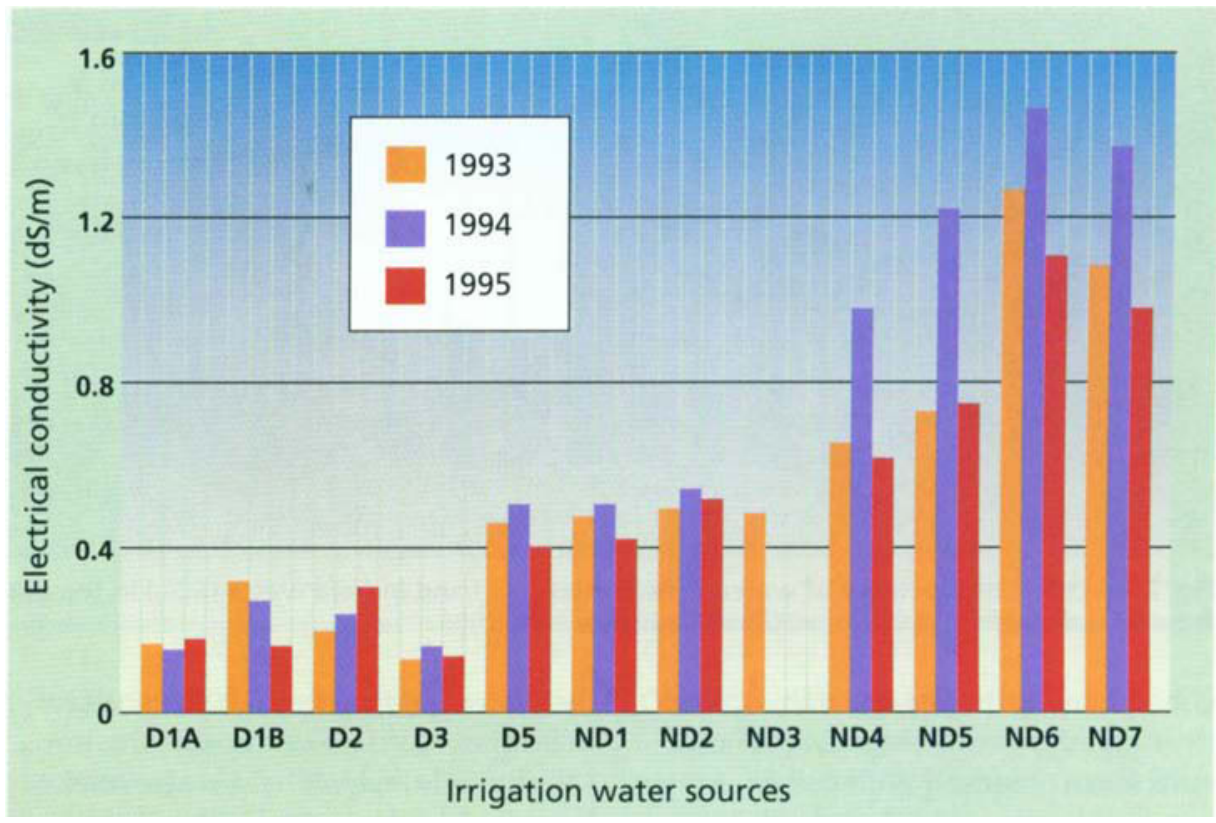

Fig. 1. Electrical conductivity among district (D) and nondistrict (ND) irrigation water sources in Glenn and Colusa counties. (Readers may e-mail srgratton@ucdavis.edu for identities of district and nondistrict irrigation water sources.)

conductance of the water supply, which is related to its saltiness.)

Irrigation districts that divert water from the Sacramento River had the lowest mean summertime salinity levels $(0.13$ to $0.31 \mathrm{dS} / \mathrm{m})$. Other district and nondistrict sources had low but slightly higher mean summertime salinity levels $(0.40$ to $0.54 \mathrm{dS} / \mathrm{m})$.

Nondistrict water sources that used a mixture of drain and well water had higher mean salinity levels $(0.62$ to 1.47 $\mathrm{d} S / \mathrm{m})$. Drain water from nonrice field sources may have also affected water quality at some sites.

The mean summertime $\mathrm{EC}_{\mathrm{w}}$ for all irrigation water sources was highest in 1994 and lowest in 1993 and 1995. For example, the mean salinity level in the Colusa Basin Drain at the Davis Weir was $1.22 \mathrm{dS} / \mathrm{m}$ in 1994 , but only 0.73 and $0.75 \mathrm{dS} / \mathrm{m}$ in 1993 and 1995 , respectively. The higher salinity levels in 1994 (compared to 1995) can likely be attributed to higher cumulative evapotranspiration (ET) and lower rainfall during the summer (June to August) months, in addition to stricter water conservation practices.

\section{Field salinity monitoring}

We also monitored 27 rice fields that used conventional, recirculating and gravity irrigation systems for salinity in Colusa and Glenn counties, annually from 1993 to 1995. Management of these fields varied considerably, as has been previously described (Hill et al. 1995). Salinity of the water was monitored at the inlet, top and bottom basins of each field in June, July and August. The June sample time was during or close to the water holding period in many of the fields studied. Soil salinity was also monitored in these fields at the same times but was not initiated until midway through the 1993 season. Some fields utilized recirculating, gravity or static systems to manage water during the water holding period while others held water for the required holding period or season-long. Yield data was collected in 1994 and 1995 from 3.3-feet-by-3.3feet ( 1 square meter) plots near the salinity monitoring locations in each of the top and bottom basins.

Mean bottom-basin water salinity levels were significantly higher than those in top basins, while EC of the inlet water was often the same as EC of the field water $\left(\mathrm{EC}_{\mathrm{fw}}\right)$ in the top basin (fig. 2). Fields with low $\mathrm{EC}_{\mathrm{fw}}$ levels showed little difference between top and bottom basins.

Data for June is presented because the water salinity levels were higher and the differences between the top and bottom basins were greater during or after the water holding period. The salinity level and relative differences between top and bottom basins de- 


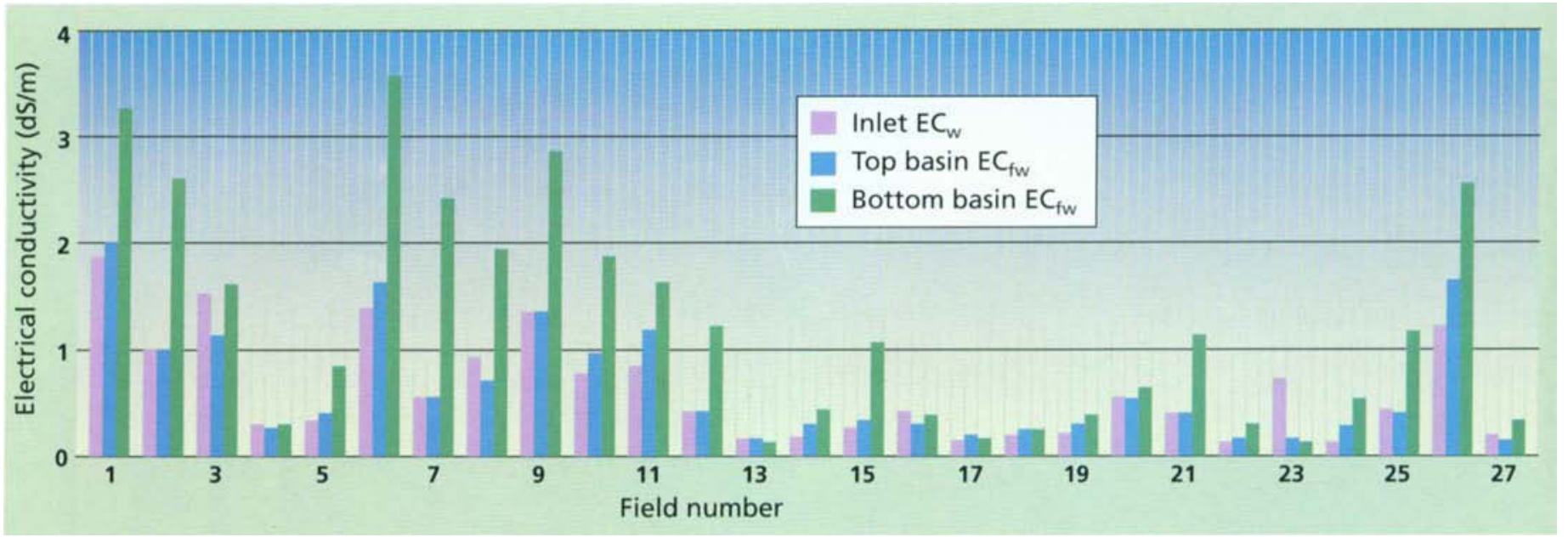

Fig. 2. Electrical conductivity of water at field inlet $\left(E C_{w}\right)$ and in field water $\left(E C_{\mathrm{fw}}\right)$ in top and bottom basins from 27 rice fields in Colusa and Glenn counties, June 1995.

clined later in the season after water flow and depths increased. Similar results were observed with soil EC (data not shown). From 1993 through 1995 , the mean $\mathrm{EC}_{\mathrm{fw}}$ for June was $0.70 \mathrm{dS} / \mathrm{m}$ in the top basins and $1.28 \mathrm{dS} / \mathrm{m}$ in the bottom basins of all fields monitored. Similar patterns were found in 1994. In fields with higher salinity levels, rice stand establishment was affected more in bottom basins than top basins.

In 1994, during the June sample, field water and soil salinity levels correlated significantly in both top and bottom basins $\left(r^{2}=0.52\right.$ and $r^{2}=0.70$, respectively). The relationship between $\mathrm{EC}_{\mathrm{fw}}$ and the average root-zone salinity $\left(\mathrm{EC}_{\mathrm{C}}\right)$ varied between top and bottom basins and at different times during the season.

In 1995, water salinity was monitored more frequently in several fields, two with high salinity and one with lower salinity. Salinity data was similar in both fields with the highest salinity, indicating that $\mathrm{EC}_{\mathrm{fw}}$ was highest during the water holding period, particularly in bottom basins. Conversely, the low salinity field, which held water seasonlong, had low salinity levels all season ( 0.1 to $0.2 \mathrm{dS} / \mathrm{m})$.

In one of the high-salinity fields, the $\mathrm{EC}$ of inlet water $\left(\mathrm{EC}_{w}\right)$ was similar to that in the top basin, regardless of time after flooding (fig. 3). During the water holding period, water salinity levels in the bottom basin increased rapidly, which we attribute to a combination of no outflow, reduced inflow rates and evapoconcentration of salts. This suggests salinity can be a serious problem in some fields during the water holding period. However, adding fresh water (lower EC) to the bottom basin toward the end of the holding period increased the field's water level and reduced salinity, indicating that monitoring and management can help moderate a salinity problem. In bottom basins of some fields, salinity increases made it difficult for some growers to hold water

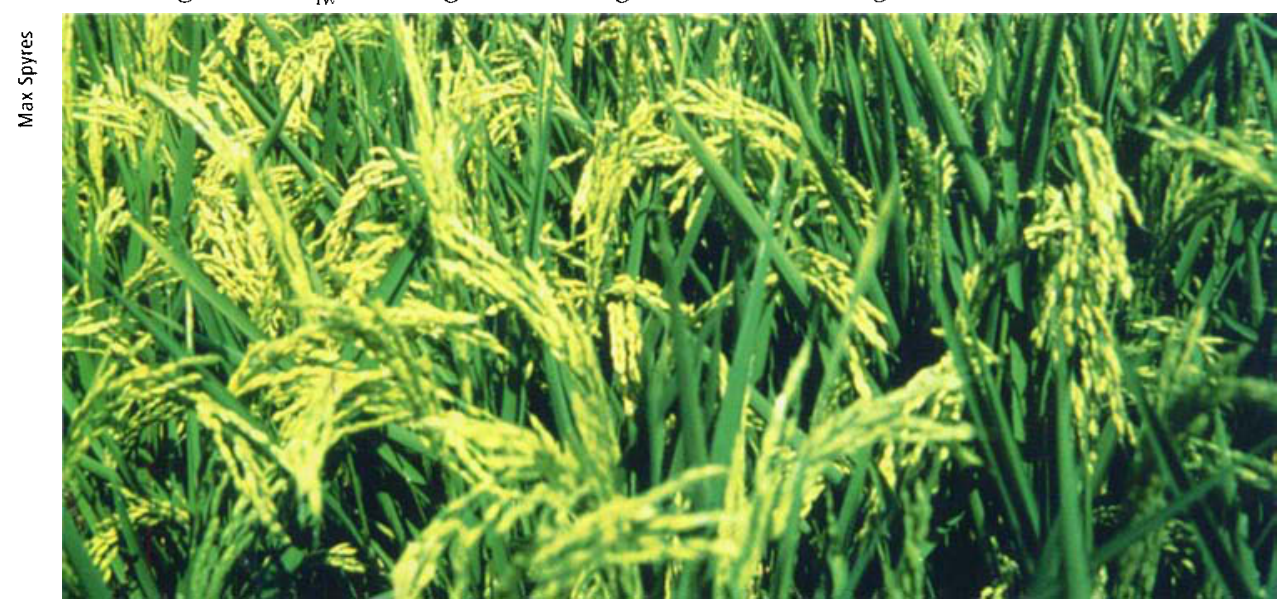

Appropriate water management in fields can help to reduce salinity damage and produce a healthier rice crop. This normal rice, above, was irrigated with water at $0.6 \mathrm{dS} / \mathrm{m}$, well below the threshold for salinity stress.

without experiencing stand problems and yield losses.

Multiyear analysis of yield data indicates a significant decrease in grain in bottom basins compared to top basins (9,700 versus 10,300 pounds/acre). Single-year analysis indicates that top and bottom basin yields were significantly different in 1994 but not in 1995 (10,960 versus 9,880 pounds/acre, respectively). The absence of yield decline in 1995 was probably due to lower EC levels in some irrigation water sources, lower cumulative ET during the season and lower salinity levels in a number of rice fields. Grattan et al. (see p. 189) subsequently conducted controlled studies to better understand and quantify the relationship between salinity, crop performance and yield.

\section{Impact of irrigation systems}

In 1997, extensive sampling was conducted in six rice fields to compare different irrigation systems and determine what influence they have on salinity patterns in the field. In the conventional system, water flows in series from basin to basin while in the static system water is independently delivered to each basin from a supply/ drain ditch perpendicular to the basins. Flap-gated pipes prevent water mixing between basins. Seventeen locations were monitored in each of an upper, middle and lower basin in each field (51 samples per field). At all locations, field water salinity was measured throughout the season and soil salinity was measured at harvest. At two sites, soil salinity was measured at midseason and yields at harvest.

These studies confirmed that water 


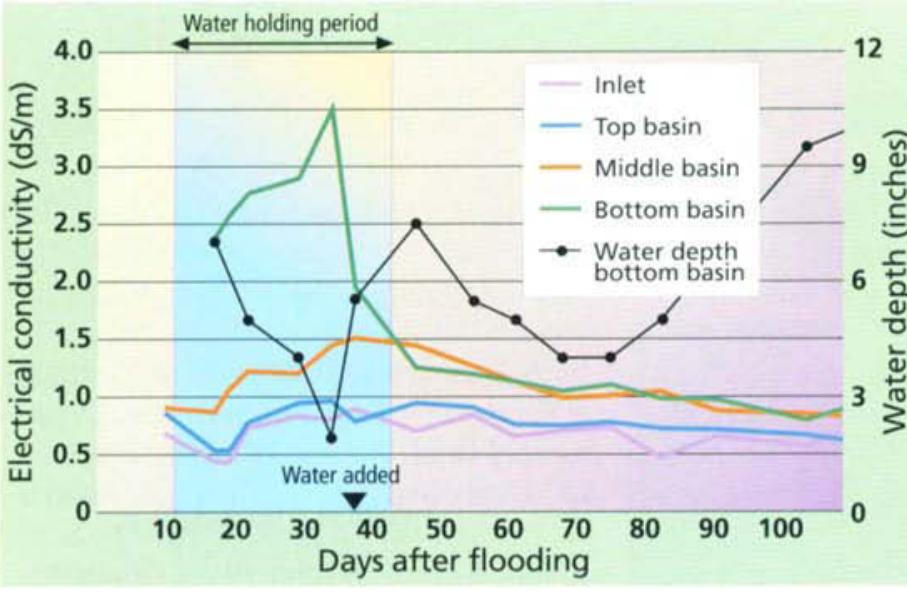

Fig. 3. Electrical conductivity of rice field water at the inlet, top, middle and bottom basins from a salt-affected field intensively monitored in 1995. The water holding period can substantially increase salinity in the bottom basin. salinity increases in bottom or lower basins to some degree in most fields during the water holding period (data not shown). They also showed that different irrigation systems influence field water salinity patterns (fig. 4A-B). In conventional systems salinity levels increased from top to lower basins. In static systems each basin was irrigated independently, and salinity levels among basins varied somewhat but were not significantly different. However, in both systems salinity increased with distance from the water inlet. The soil salinity and water flow patterns may contribute to spatial variation between and among basins in the static irrigation systems. After the water holding period, differences among and within basins declined sharply. $\mathrm{EC}_{\mathrm{fw}}$ levels increased during the water holding period, but decreased later when irrigation water was again added to the field.

In the static system, the measured peak $\mathrm{EC}_{\mathrm{fw}}$ occurred at the middle of the water holding period - water was added just prior to the late sample time, most likely lowering the EC level. Although not illustrated in figure 4 , data from earlier studies showed increases in late-season $\mathrm{EC}_{\mathrm{fw}}$ levels in static and other closed-basin systems. The mean EC. (51 samples) for all basins was 3.1 $\mathrm{dS} / \mathrm{m}$ in the conventional and $1.7 \mathrm{dS} /$ $\mathrm{m}$ in the static system.

Yield data from the 1997 field study was inconsistent. $\mathrm{EC}_{\mathrm{fw}}$ at one location, which ranged from less than $1 \mathrm{dS} / \mathrm{m}$ to greater than $4.0 \mathrm{dS} / \mathrm{m}$ at the end of the water holding period, was negatively correlated with reduced stand $(r=-0.38$, mean water holding period $\mathrm{EC}_{\mathrm{fw}}$ versus stand density), but not to yield $(r=0.29)$. At this site, poor weed control in the top basin had likely affected yield more than salinity in the bottom basin, thereby reducing the salinity-yield correlation. At a second location with lower salinity levels but a similar salinity range, stands $(r=-0.22)$ and yields $(r=-0.30)$ were negatively correlated with $\mathrm{EC}_{\mathrm{fw}}$ during the water holding period.

\section{A}

Conventional irrigation system field schematic

Early WHP, 12 DAP

Late WHP, 37 DAP

it
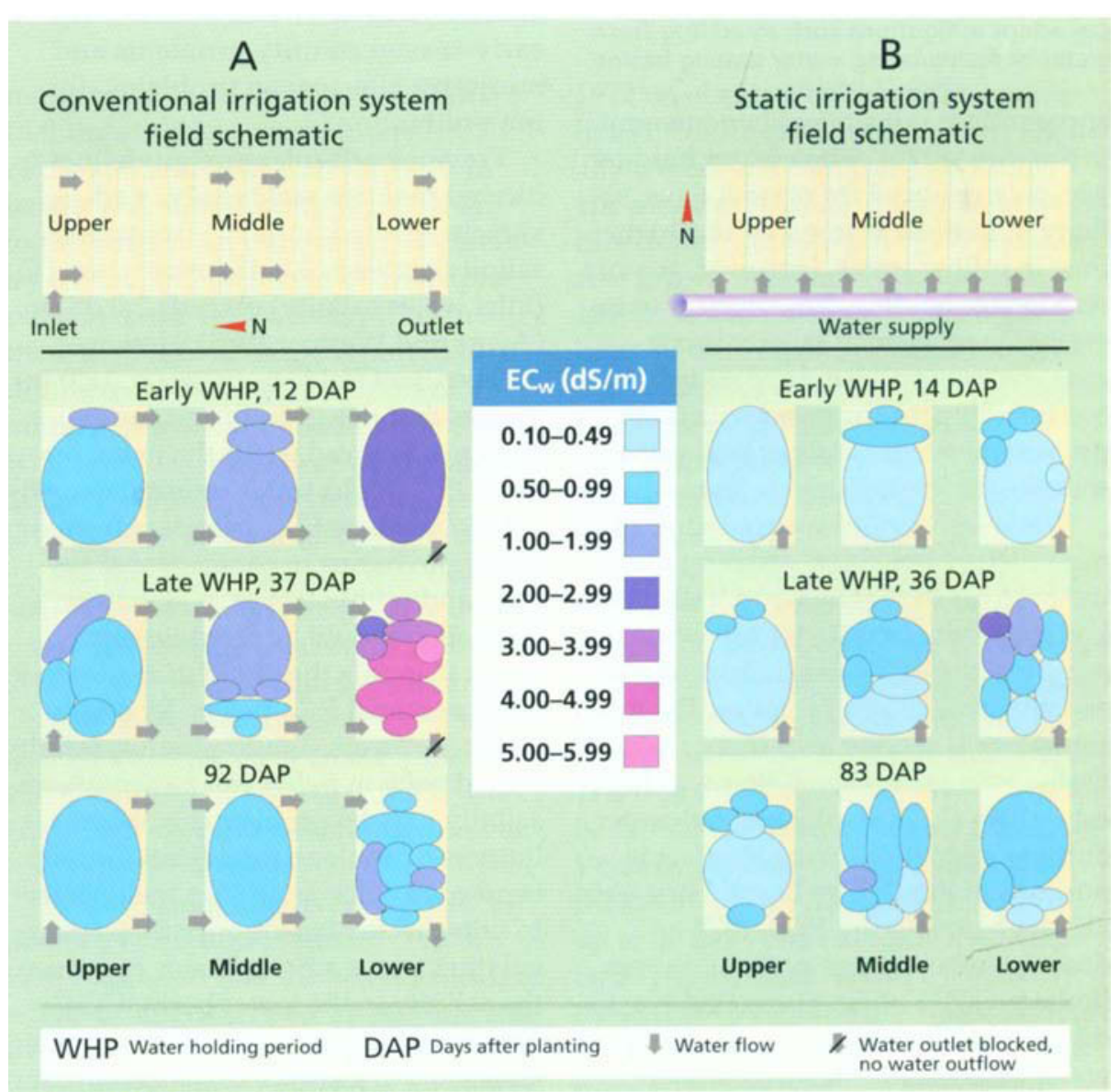

\section{Coping with salinity}

Rice growers have made great strides in reducing pesticide loads into rivers by holding water on fields longer and using various alternative irrigation systems. At the same time, increased soil and water salinity levels, particularly in bottom basins, have been associated with reduced rice stands and yield. Higher salinity in bottom basins
Fig. 4. Field water electrical conductivity patterns in rice fields with (A) conventional and (B) static irrigation systems, at three monitoring times after planting. 

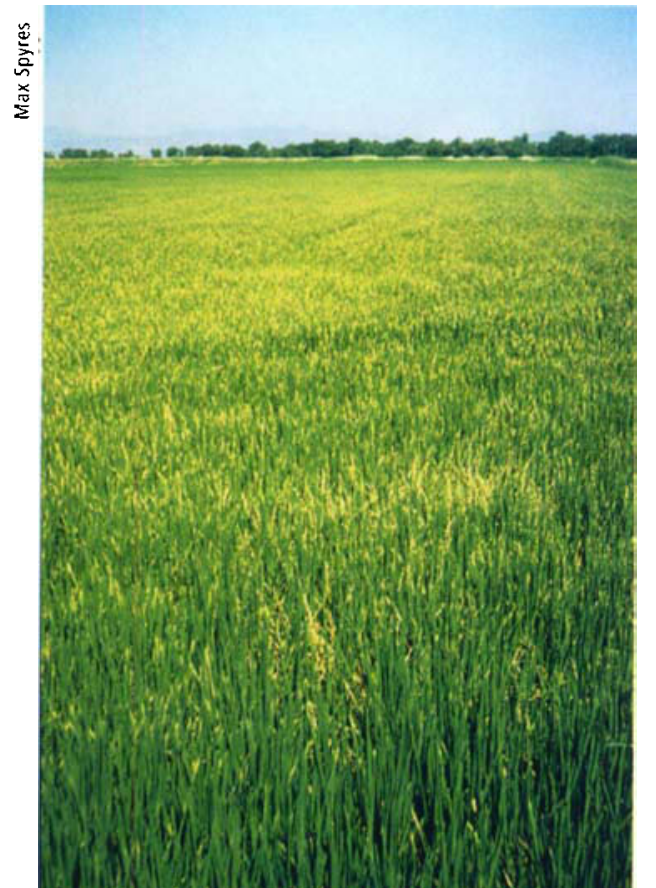

Above, Rice grown in water at $6.8 \mathrm{dS} / \mathrm{m}$, two to three times the threshold for salinity damage, shows severe leaf necrosis. In basins where salinity is a problem, growers can adopt mitigations such as adding fresh water or recirculating water among basins.

apparently is not a new phenomenon: in the early 1970s, when water holding was only required for several days, salinity in outflow water was also higher than in inflow water. However, the current longer holding times appear to increase the problem in salinity-prone areas. Salinity problems appear to be exacerbated in areas irrigated with nondistrict water from drain or well water sources with higher salinity levels.

When our studies were conducted, most district irrigation water on the west side of the Sacramento Valley was low in salinity $(<0.70 \mathrm{dS} / \mathrm{m})$, while some nondistrict water had salinity levels between 0.70 and $1.5 \mathrm{dS} / \mathrm{m}$. The mean summertime salinity level in the Colusa Basin Drain at the Davis Weir was highest in $1994(1.2 \mathrm{dS} / \mathrm{m})$ when tail-water outflow restrictions were in effect in portions of the Colusa Basin. They were also high during the 1976-1977 drought, when water availability was limited (GCID 1997). These findings indicate that the quality of nondistrict water sources may be adversely affected under conditions of low water availability or restricted flow.
Salinity levels increased in bottom basins particularly during the early season when water holding periods of more than 30 days were in effect. In some fields where salinity was excessive, grain yield was significantly reduced. In contrast, water can be held for the same period in fields low in salinity without affecting yields.

The type of irrigation system and pattern of water flow greatly influenced salinity patterns in fields. In conventional and static systems, salinity levels increased as the distance from the water inlet increased. Salinity was highest in these areas during the earlyseason water holding period. Water depths in rice fields are typically raised to about 8 inches at 60 to 70 days after planting to protect the developing pollen from cold nighttime temperatures. Raising water at this time dilutes salts in the field water, countering the increased salinity resulting from evapoconcentration. This is important as it helps to moderate and control early-season salinity problems and minimize late-season problems during pollination.

Previous salt-tolerance guidelines indicated that rice yields are not adversely affected until $\mathrm{EC}_{e}$ (root-zone salinity) exceeds $3.0 \mathrm{dS} / \mathrm{m}$ or when $\mathrm{EC}_{w}$ (inlet water salinity) exceeds $2.0 \mathrm{dS} / \mathrm{m}$ (Ayers and Westcot 1985). However, an independent field study (see p. 189) indicates that rice growth and/or grain yield are reduced when the mean seasonal $\mathrm{EC}_{\mathrm{fw}}$ (field water salinity) exceeds $1.9 \mathrm{dS} / \mathrm{m}$. Since $\mathrm{EC}_{\mathrm{fw}}$ increases from top to bottom basins in conventional systems and within basins in static systems, $\mathrm{EC}_{\mathrm{w}}$ should be substantially lower than this threshold to maintain a mean seasonal $\mathrm{EC}_{\mathrm{fw}}$ below $1.9 \mathrm{dS} / \mathrm{m}$.

Rice growers should monitor salinity periodically in fields and basins where salinity may be problematic. When salinity is a problem, modifications may be needed, such as adding fresh water to salt-affected basins or perhaps recirculating water among basins to reduce the salinity in the lower basin. UC Cooperative Extension can offer valuable assistance to growers in diagnosing salinity problems and better managing rice farms.
S.C. Scardaci is former Farm Advisor, UC Cooperative Extension, Colusa County, UC Davis; M.C. Shannon is Research Geneticist, USDA-ARS George E. Brown, Jr. Salinity Laboratory, Riverside; S.R. Grattan is Plant-water Relations Specialist, Department of Land, Air and Water Resources, UC Davis; and A.U. Eke and S.R. Roberts are former Staff Research Associates, $S$. Goldman-Smith is former Post Graduate Researcher, and J.E. Hill is Agronomist, Department of Agronomy and Range Science, UC Davis. We would like to acknowledge the late Max Spyres, former Colusa County rice grower, for his pioneering work in identifying salinity as a problem in local rice fields and for his preliminary studies on the problem. Max's encouragement was instrumental in conducting this work. We also thank the numerous rice growers whose cooperation made this work possible. This project was partially funded through the USDA Presidential Water Quality Initiative: The Sacramento River Rice Water Quality Demonstration Project, number 94-EWQD-9520.

\section{References}

Ayers RS, Westcot DW. 1985. Water quality for agriculture. FAO Irrigation and Drainage paper No 20 (rev. 1). FAO United $\mathrm{Na}$ tions, Rome, Italy. $174 \mathrm{p}$

[GCID] Glenn-Colusa Irrigation District. 1997.

Water Measurement Report. Willows, CA.

Henderson DW, Tanji KK, Biggar JW, et al. 1974. Water Quality in Rice Fields. Water Science and Engineering Papers 4008, Dept. of Water Science and Engineering (now Land, Air and Water Resources), UC Davis.

Hill JE, Scardaci SC, Roberts SR, et al. 1995. Rice irrigation systems for tailwater management. UC DANR Pub 21490 (revised). 14 p.

Khatun S, Flowers TJ. 1995. Effects of salinity on seed set in rice. Plant Cell Environ 18:61-7.

Lee MJ, Ross LJ, Wang RG. 1993. Integrating environmental toxicology and monitoring in the development and maintenance of a water quality program: California's rice herbicide scenario (Ch. 18). In: Jolley FL, Wang RGM (eds.). Effective and Safe Waste Management: Interfacing Sciences and Engineering with Monitoring and Risk Analysis. Ann Arbor, MI: Lewis.

Maas EV. 1990. Crop salt tolerance. In: Tanji KK (ed.). Agricultural Salinity Assessment and Management Manual. ASCE Manuals \& Reports on Engineering Practices No 71. New York. p 262-304.

Shannon MC, Rhoades JD, Draper JH, et al. 1998. Assessment of salt tolerance in rice cultivars in response to salinity problems in California. Crop Sci 38:394-8. 